After the Choosing Ceremony: Using Role-Play to Teach Organizational Socialization

\author{
Kaitlin E. Phillips \\ Utah State University
}

Katherine E. Forsythe

Texas Christian University 


\section{After the Choosing Ceremony: Using Role-Play to Teach Organizational Socialization}

Course: Organizational Communication

Objectives: The goal of this activity is to teach students about the stages of Organizational Socialization and how individuals might be socialized into an organization based on given the identity of that organization.

Theoretical rationale: One process that each of us experience at least once in our lives, is the process of organizational socialization. This ongoing process of organizational socialization includes multiple components (Miller, 2015), such as how we seek information and reduce uncertainty when joining an organization. Socialization works to help individuals become fully integrated members of the organization (Jablin, 2001; Kramer, 2010; Miller, 2015). One set of phases scholars have used to talk about organizational socialization are anticipatory, encounter, and metamorphosis (Miller, 2015). Specifically, the encounter phase occurs "when a new employee enters the organization" and learns to make sense of their role in the organization (p. 121). Understanding how and in what ways individuals are socialized into an organization varies based on the unique mission, values, and identity of the organization - the organizational culture (Kramer, 2010). Thus, considering the unique identity of the organization is integral to students' ability to recognize that socialization is a process and not a specific set of steps that are exactly the same in every organization. In other words, the ways in which an individual moves through the encounter and metamorphosis stages is largely dependent on the organizational culture and climate, because the strategies used to help organizational members assimilate is dependent on context (Miller, 2015).

Every time we join an organization, we go through the socialization process, which is often not as explicit as we might like, although organizations often provide handbooks for role-related information, there is no such formal structure for cultural information. In order to understand the socialization process and the value it has for both the individual and the organization, it is important to learn about the socialization process within the context of an organization's culture. Specifically, individuals are assimilated into an organization through such things as "formal training programs, mentoring, interviewing, outside research, and relationships with managers, coworkers, and subordinates" (Miller, 2015, p. 125). Consequently, it is the organizational culture that dictates how these formal and informal processes are prioritized and operationalized. Thus, in order to help students learn about the process of organizational assimilation, we chose a popular culture book/movie series to help illustrate how organizational culture is integral to these assimilation processes from the perspective of the organization. According to Muddiman and Frymier (2009), movie clips and popular culture items are valuable in helping students find relevance in the course content. Specifically, students identified the use of clips and popular culture items as key components of making course content relevant outside of the confines of class. Thus, we set out to utilize a popular book/movie series to help students engage with a complex concept and see how it could be applied.

The Divergent book/movie series involves a population of five sects of people who are grouped based on particular characteristics (e.g., honesty, intelligence, bravery, selflessness, and kindness). Once individuals in this dystopian society reach the age of 16 they are given an aptitude test, and then are allowed to choose which faction they will spend the rest of their lives. 
Although the premise is that individuals do not have much choice because they are expected to select their faction based on the test results, they are still given the opportunity to pick any of the five factions.

Each faction's identity has been exaggerated for the sake of the plotline; however, it is these overemphasized group qualities that make these factions ideal for illustrating how organizations might explicitly and implicitly socialize a new member into the organization. There are also specific examples within the films that could be shown to demonstrate how these factions socialize new members. For example, the main character Tris, chooses to join the faction Dauntless (known for being brave), and the first thing they make her do is jump onto a moving train to demonstrate their courage and commitment.

Given the strong and singular identity each faction possesses, students were able to quickly and easily identify what makes that faction unique, and how that faction would socialize new members. Using the premise of factions, students were challenged to engage with the material and critically think about what the socialization process might look like for each individual faction (organization). Students were asked to demonstrate their understanding of socialization concepts by applying them to a specific faction. Specifically, they demonstrated how the identity or culture of that faction drives the ways in which members are socialized into the organization.

Activity Description: 30-50 minutes

Materials:

- Divergent Movie Clips

- Divergent Faction Quiz https://www.buzzfeed.com/ariellecalderon/which-divergentfaction-do-you-actually-belong-in

- For each group: Activity Instruction Handout and Divergent Faction Descriptions

- List of students and their assigned faction

Opening Scene: Societal Structure and Factions are Introduced. 2:28-4:10

https://www.youtube.com/watch?v=hVCrQleRZmc

Choosing Ceremony: How Individuals Make Decisions about Joining Factions. .45sec-4:55 https://www.youtube.com/watch?v=klGMA7PHWhw

The goal of this activity is create a socialization program for a new member entering one of the Divergent factions. This activity requires minimal preparation and usually works best after the basics of organizational socialization (i.e., chapter 7 in the Miller (2015) textbook) have been covered. Specifically, students were assigned to read the chapter and attended a class lecture prior to this assignment. In addition, in the prior class period students are shown two brief clips about Divergent and the factions to help them think about the setting (links to videos above). Finally, students are assigned a faction aptitude test prior to the class activity. The online quiz takes less than 5 minutes, and provided students with a stronger connection to the faction that they were assigned to for the activity. Students emailed the instructor their results prior to class, and those results were used to determine which faction individuals were assigned to. If students choose not to participate in this aspect of the activity, they were assigned to groups based on the number of individuals needed for each group. If too many students were assigned to the same faction, then students were assigned to their second highest faction. We used an entire 50-minute class period for this activity. 
On activity day, students were divided up into their Factions and given a set of instructions and a description of their faction. Students prepared an socialization program for their faction, based on how they would socialize a new member. This activity was assessed for a grade in order to motivate students to actively participate and to evaluate how well they were able to demonstrate their understanding of the intended course concepts.

\section{Activity Instruction Handout}

We created a student handout that included the following instructions and information: Prepare a report for how your faction would train a new member. Use the following questions to guide your report:

1. How would you orient a new faction member?

2. Are there specific tests new members have to pass? If so what do they look like?

3. What are the goals of your formal and informal orientation program?

4. What activities should be used to help assimilate new members into the role-related and cultural-related information?

5. How can this informal and formal orientation program be unique to your faction?

Make your responses specific to the identity of your Faction. Please incorporate class concepts from chapter 7 (Miller, 2015) into a well-thought-out, concise description. Your ability to incorporate concepts from chapter 7 and to develop a program that is true to the identity of your Faction will be how the Quiz grade is determined. This is a group grade. At the end of class you will submit a typed report. The grading rubric indicates how your typed report will be graded. See below for a description of your Faction.

\section{Faction Handout}

"In Divergent, society is divided into five factions, each dedicated to the cultivation of a particular virtue. When the factions were formed, however, each gained a negative and a positive trait. The factions are: Abnegation, Erudite, Dauntless, Amity, and Candor. On an appointed day of every year, all sixteen-year-olds must select the faction to which they will devote the rest of their lives after taking an aptitude test." (http://divergent.wikia.com/wiki/Factions, 2019, para 1).

All individuals in this society know about the other factions, they have received faction history, and up until the time of their choosing all of the factions go to school together. Thus, they have been engaged in anticipatory socialization - vocational and organizational socialization has occurred as they learn about the different factions, the factors and traits that make them different, and the jobs that each faction is responsible for in society. On Choosing Day, individuals make a decision about which faction they want to join - in other words they have agreed to join that organization for life...on one condition-don't get "fired." Should the faction decide you are not a good fit, you join the factionless - those who don't fit anywhere. As individuals who are already key members of the following faction you are responsible for determining how you will socialize new members into your faction, and ultimately determine if they are a good enough fit to stay forever. 
Note: Included in this handout for each group should be a description of the Faction this group was assigned On the Wiki Fandom Page you will find descriptions of each of the factions to provide to the students. http://divergent.wikia.com/wiki/Factions

\section{Assessment Recommendations:}

For this assignment, quiz points were associated with the product the students produced. As a group, students were graded on their ability to produce a plan for the assimilation process that is unique to their faction, and their ability to incorporate concepts from organizational socialization (i.e., Chapter 7 in Miller, 2015). Prior to incorporating the Divergent theme into this assignment, when students were asked to develop an assimilation process for their "organization," they struggled to determine their unique identity, and instead got lost in creating a process that might more aptly be termed hazing. Thus, the goal of this activity was to give students a clear and distinct identity to work with as they learn the socialization process. When students used the Factions as their group identity, they did a much better job of connecting course concepts to the activity, and clearly identifying how and why it is important to socialize new members into the organization. As a whole, groups did a better job including course concepts and understanding the connection between organizational culture and the socialization process.

Grading Rubric: Faction Assimilation 20 points

\begin{tabular}{|l|l|l|l|}
\hline Concept & $\begin{array}{l}\text { Group exceeded } \\
\text { expectations }\end{array}$ & $\begin{array}{l}\text { Group met } \\
\text { expectations }\end{array}$ & $\begin{array}{l}\text { Group did not } \\
\text { meet expectations }\end{array}$ \\
\hline $\begin{array}{l}\text { Students created an } \\
\text { orientation program that } \\
\text { encapsulates the culture of } \\
\text { their faction. }\end{array}$ & $\begin{array}{l}10 \\
\text { The whole orientation } \\
\text { program is clearly } \\
\text { connected to the } \\
\text { assigned Faction }\end{array}$ & $\begin{array}{l}\text { Some of the } \\
\text { orientation aspects } \\
\text { are clearly } \\
\text { connected to the } \\
\text { assigned Faction }\end{array}$ & $\begin{array}{l}\text { 1 or none of the } \\
\text { orientation } \\
\text { aspects are clearly } \\
\text { connected to the } \\
\text { assigned Faction. }\end{array}$ \\
\hline $\begin{array}{l}\text { Students correctly } \\
\text { referenced and identified } \\
\text { concepts from chapter 7 } \\
\text { of Miller, 2015 in their } \\
\text { orientation program. }\end{array}$ & $\begin{array}{l}\text { Students correctly } \\
\text { referenced at least 5 of } \\
\text { the concepts from } \\
\text { chapter 7. }\end{array}$ & $\begin{array}{l}\text { Students correctly } \\
\text { referenced at least 3 } \\
\text { of the concepts } \\
\text { from chapter 7. }\end{array}$ & $\begin{array}{l}\text { 4 } \\
\text { Students correctly } \\
\text { referenced 1 or } \\
\text { none of the } \\
\text { concepts from } \\
\text { chapter 7. }\end{array}$ \\
\hline
\end{tabular}




\section{References}

Divergent (n.d.). Factions. Retrieved on February 1, 2018, from:

http://divergent.wikia.com/wiki/Factions

Jablin, F. M. (2001). Organizational entry, assimilation, and disengagement/exit. In F. M. Jablin \& L. L. Putnam (Eds.), The new handbook of organizational communication: Advances in theory research and methods (pp. 732-818). Thousand Oaks, CA: Sage.

Kramer, M. W. (2010). Organizational socialization: Joining and leaving organizations. Cambridge, UK: Polity Press.

Miller, K. (2015). Organizational communication: Approaches and processes (7th ed.). Stamford, CT: Cengage.

Muddiman, A., \& Frymier, A. (2009). What is relevant? Student perceptions of relevance strategies in college classrooms. Communication Studies, 60, 130-146.

doi:10.1080/10510970902834866. 